\title{
A descriptive qualitative study of childhood cancer challenges in South Africa: Thematic analysis of 68 photovoice contributions
}

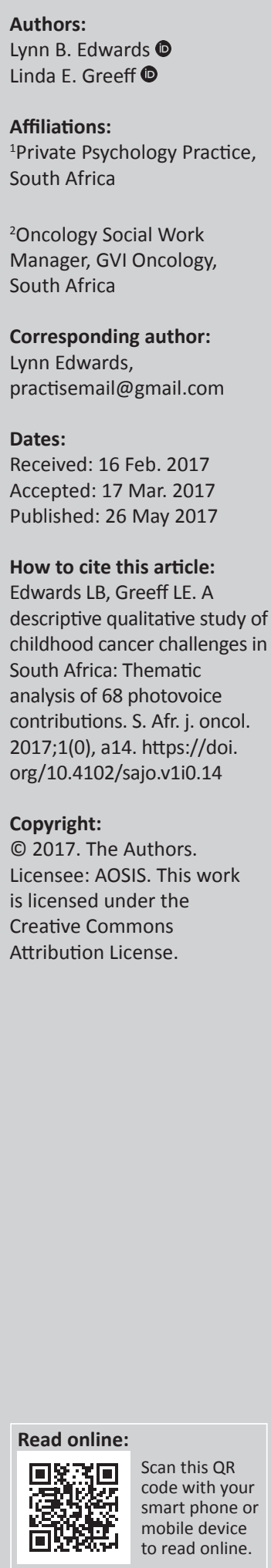

Background: Many childhood cancers are treatable with cure rates between $70 \%$ and $80 \%$ in well-resourced countries, while approximately $80 \%$ of African children with cancer die without access to adequate care. South Africa has an established oncology health care service with overburdened infrastructure, low cancer awareness in the primary health care service and widespread service delivery challenges.

Aim: The aim of this study was to explore, document and analyse the subjective experience of childhood cancer-related challenges in South Africa, and to make the results available to stakeholders.

Setting: A total of 58 patient-participants (childhood cancer patients, parents and guardians of children with cancer) and 10 paediatric oncology workers (oncology social workers, oncology nurses and interim home carers) were selected from tertiary oncology centres and from the Childhood Cancer Foundation of South Africa (CHOC) interim care homes across South Africa.

Method: Participants were selected via convenience sampling and qualitative data were derived from face-to-face photovoice interviews conducted by psychologists and social workers and supported by translators when necessary.

Results: Nine themes of cancer challenges were identified via thematic content analysis of the photo-narratives, that is, physical and treatment challenges, emotional, poor services, transport, finances, information, powerlessness, stigma and schooling challenges.

Conclusion: Lack of awareness and knowledge about cancer at the African traditional healer, primary and regional health care service levels were frequent challenges. Important feedback included lack of patient-centred care, separation of children with cancer from guardians, diagnostic delays, permanent disabilities for children because of cancer, emotional trauma, special needs of teenagers and a lack of community and palliative care support.

\section{Introduction}

Many childhood cancers are treatable with cure rates of up to $80 \%$ in well-resourced countries. ${ }^{1}$ With an emphasis on communicable diseases, low-and middle-income countries (LMIC) including those in Africa have not prioritised cancer or childhood cancer in public health policy, ${ }^{2}$ and it is suggested that approximately $80 \%$ of African children with cancer still die without access to adequate care. ${ }^{1,3,4}$

Accurate data about childhood cancer and the impact of the disease are rare in Africa, ${ }^{5}$ and South Africa (SA) is the only country with a national childhood cancer registry. ${ }^{4,6}$ Frequent late stage presentation and high mortality make cancer a serious public health issue throughout Africa ${ }^{7,8,9}$ and better outcomes for children with cancer depend on improved cancer planning, resource development and access to care. ${ }^{1,2}$

Photovoice methodology ${ }^{10}$ was chosen as a qualitative research tool because it encourages storytelling about everyday life, is a user-friendly information capturing tool ${ }^{11}$ and can facilitate information flow from service users to health care stakeholders. ${ }^{12}$ Photovoice data collection has been used with both children ${ }^{13}$ and adults in health research and advocacy for social change. ${ }^{14,15}$ Through the qualitative information encoding of photovoice narratives, photovoice material has also been used as a source of qualitative data. ${ }^{11}$ 
In response to the very limited research on the subject, this study explores the subjective experience of cancer-related challenges in SA in a sample of parents or guardians of children with cancer, young patients with cancer and paediatric oncology workers.

\section{Research methods and design Study design}

This qualitative, participatory action research design ${ }^{10}$ facilitates the direct use of participant views of childhood cancer-related challenges (i.e. photo-stories), in social action (i.e. cancer advocacy).

\section{Aim}

The aim of this study was to document and thematically analyse photovoice contributions of childhood cancer-related challenges in SA, to promote understanding of the childhood cancer care landscape and for photovoice contributions to be used for cancer advocacy.

\section{Setting and study population}

A total of 58 parents and guardians of children with cancer, childhood cancer patients themselves (called patientparticipants) and 10 paediatric oncology workers were selected via convenience sampling from tertiary oncology centres and the Childhood Cancer Foundation of South Africa (CHOC) interim care homes across SA. The patientparticipants comprised 36 mothers, 12 grandmothers, 3 fathers, 1 female (19 years) and 1 male sibling (22 years), 1 aunt and 3 female children and 1 male child who had cancer. Four children were interviewed without input from their parents: three young female patients aged 11, 11 and 13 years, and a young male patient aged 17 years.

\section{Data collection}

All participants were interviewed via face-to-face interviews using photovoice methodology ${ }^{15}$ and by clinical social workers or psychologists to ensure that interviews were sensitively patient-centred. Information about age, gender, hometown, treatment town, public or private medical care and childhood cancer type was also collected. Two openended questions were asked in the photovoice interview process and answers were documented as colloquial narratives (Question 1: What would you like to say about having cancer or about someone close to you who has had cancer? Question 2: Are there specific problems that you think need to be spoken about so that things can be improved?).

Participants were invited to choose a photographic image that could represent their story; cameras were provided and participants were supported through the playful activity of taking a photograph that visually referred to their story (Figure 1). The photograph was then combined with the documented photo-narrative to form a set of advocacy materials (Figure 2). Written consent was obtained

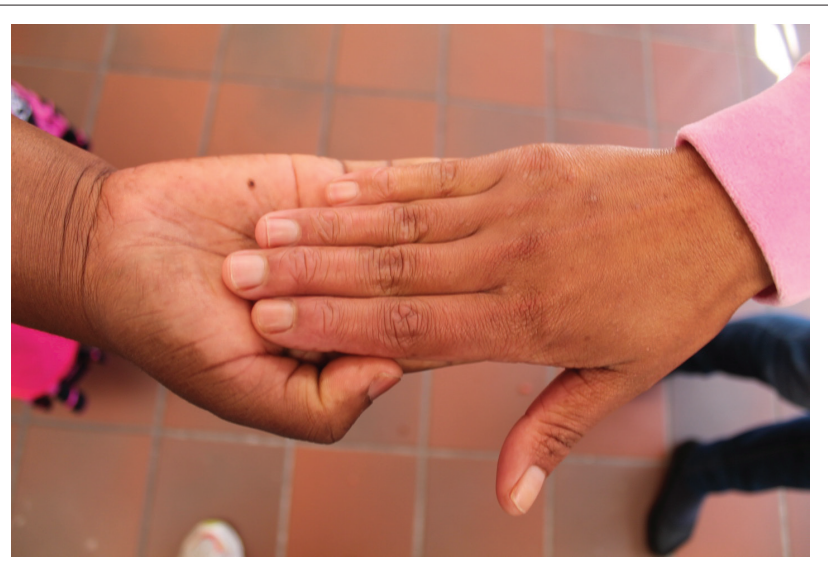

Source: Photo by Lynn Edwards

This photograph was titled 'Mothers supporting each other' and had a message about the importance of peer-support for parents of children with cancer, that is, 'I chose to take this photograph because the help of the other mothers is so important when your life is turned upside down.' (PvM214, Mother of 7-year-old son; liver cancer; Port Elizabeth)

FIGURE 1: An example of a photograph chosen to illustrate the message of the photo-story.

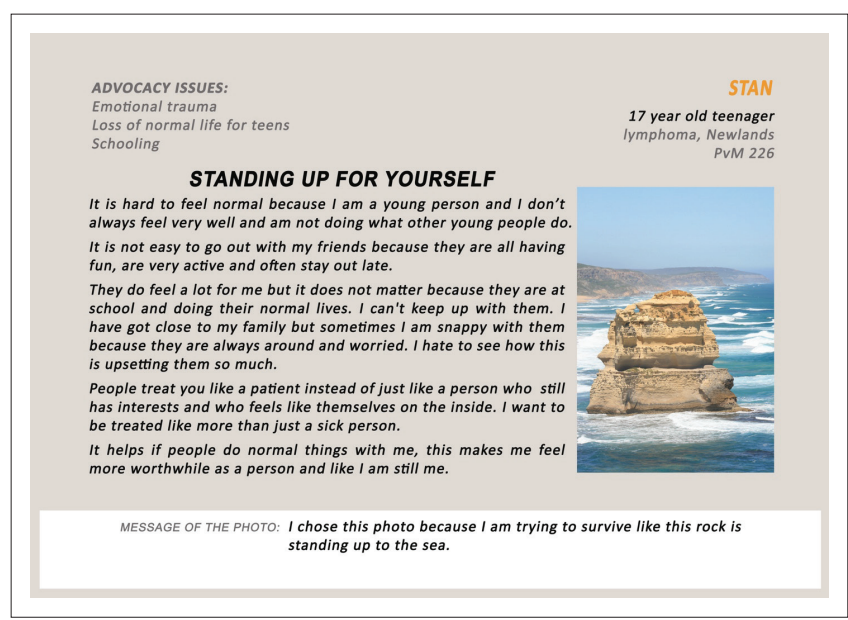

Source: Photo by Lynn Edwards

FIGURE 2: An example of a photovoice advocacy poster comprising the selected photograph and the associated photo-narrative.

for participation in this study and for the use of photovoice contributions in advocacy projects such as exhibitions, education material, stakeholder feedback meetings and patient information resources.

\section{Data analysis}

Content analysis and inductive thematic encoding ${ }^{16}$ of the colloquially documented photo-narratives were then applied using three coders to support validity through triangulation and inter-coder reliability. ${ }^{17}$ Coding was done into categories of similar content and nine themes of cancer challenges emerged.

\section{Ethical consideration}

A team of multiracial, multilingual, female professional social workers and psychologists conducted patient-centred photovoice interviews working with translators to accommodate illiteracy and indigenous languages. Ethical review and clearance was granted by the Ethics and Research 
Committee of the Medical Research Council of South Africa (EC006-3/2014), and strict guidelines for informed written consent for both adults and children (and from parents and guardians in the case of children) were adhered to.

\section{Results}

A total of 58 patient-participants and 10 oncology care workers were interviewed from 41 different towns of residence across the country and representing 9 regions (i.e. Eastern Cape: 16; Free State: 4; Gauteng: 13; Kwazulu-Natal: 15; Lesotho: 2; Limpopo: 5; North West: 7; Northern Cape: 2; and Western Cape: 4$)$. The analysis yielded little difference in the findings between the patient-participants and oncology care workers. Where of interest, the patient-participant results are distinguished; otherwise, the results are reported together. Fifty-two (77\%) patient-participants lived further than $50 \mathrm{~km}$ from an oncology tertiary treatment centre and were noted as distant-to-treatment residents. The ages of the children with cancer who were represented by the patient-participant photovoice interviews ranged from 8 months to 18 years of age, and 14 different cancer diagnosis as understood by the patient-participants themselves were reported, that is, acute lymphoblastic leukaemia $(n=23)$, kidney cancer $(n=9)$ and brain cancer $(n=8)$, lymphoma $(n=5)$, cancer of the eye $(n=3)$, myoepithelial carcinoma $(n=2)$, Fanconi anaemia with leukaemia, sarcoma, rhabdomyosarcoma, abdominal, liver, thyroid and sinus cancer and one diagnosis was unknown. After the inductive thematic coding and abstraction process was applied to the photo-narratives, nine themes of cancer challenges were identified.

\section{Emotional challenges theme}

'I feel ill from being so upset all the time.' (PvM315, Mother of 8-year-old son; leukaemia)

Emotional challenges were mentioned by 67 out of 68 participants. Most of the younger children appeared to cope emotionally when they were secure with their guardians, while 30 participants spoke of severe parental and family member distress and anxiety. Parental and family distress related to subthemes of employment, financial concerns, separation of families, fear and uncertainty about the childhood cancer patient's health and concern for siblings left at home. Twenty-nine contributors indicated positive emotional experiences with high value placed on family and community support $(n=19)$, peer patient support $(n=4)$, positive care from medical staff $(n=13)$ and spiritual faith $(n=10)$. The four children who participated for themselves in the study all reported being upset because of missing friends, missing school, feeling different to their peers and being concerned about their families.

\section{Information challenges theme}

'Understanding what is happening to your child is very important.' (PvM222, Mother of 9-year-old daughter; brain cancer)
Lack of access to information was reported by 28 contributors and receiving good information was reported by nine contributors. Serious delays in accessing treatment were reported as a result of lack of public information about cancer $(n=16)$, lack of knowledge of cancer by primary care staff $(n=7)$ and low awareness of early signs of cancer by traditional healers $(n=11)$. Frustration with inadequate information about diagnosis and treatment $(n=16)$, need for discharge and home nursing information $(n=10)$ and need for information about financial assistance and transport logistics $(n=6)$ were noted. Parents and guardians reported exclusion from access to information because of not being permitted to stay with their children during medical examinations or at primary and regional hospitals $(n=10)$, lack of access to doctors $(n=7)$, language barriers and the absence of translation services $(n=4)$.

\section{Physical and treatment challenges theme}

'I hated having the seizures, it was horrible.' (PvM44, 11-year-old girl; acute lymphoblastic leukaemia)

Physical challenges were highlighted in $41 \%$ of the patient interviews and included pain and fever $(n=14)$, sores in the mouth and ears $(n=3)$, headaches and seizures $(n=4)$, appetite and weight loss $(n=2)$, loss of teeth $(n=2)$, low energy $(n=6)$ and a bad smell from the nose $(n=1)$. Side effects of surgery and radiotherapy were rarely noted and chemotherapy challenges $(n=8)$ included nausea, dizziness, fatigue, struggle with memory, medication side effects, hair loss, trauma of intravenous cannula and parental anxiety. Disabilities were noted as traumatic and included losing the ability to walk ( $n=$ $3)$, loss of an eye and blindness $(n=2)$, facial disfigurement $(n$ $=1)$, amputation of an arm $(n=1)$, mood changes $(n=2)$ and loss of speech $(n=1)$. The trauma of relapse or recurrence of cancer $(n=5)$ was reported as prolonging separation of families and escalating emotional trauma and disruption.

\section{Powerlessness challenges theme}

'I was not allowed to stay in hospital with my grandchild as she was over 8 years, I did not know how to find out what was happening to her.' (PvM287, Grandmother of 10-year-old granddaughter; acute lymphoblastic leukaemia)

General challenges of powerlessness $(n=20)$ were mentioned with specific feelings of powerlessness because of the threat of cancer $(n=8)$, lack of communication $(n=8)$, lack of understanding of one's child's cancer $(n=5)$ and not knowing how to cope with cancer $(n=6)$. Parents indicated issues of powerlessness when medical staff made decisions that impacted negatively on them or on their child $(n=8)$ and in some traditional communities, mothers were similarly powerless when they were prevented by their families from travelling away from home to seek treatment for their sick child $(n=4)$. One parent in the study managed to assert herself in response to an intimidating situation while her child was in a hospital, while 33 contributors elected to use photos depicting themselves and family members in their 
photovoice contributions choosing to be personally visible in their support of the advocacy objectives of the study.

\section{Challenges of poor services theme}

'The clinic kept thinking it was worms or HIV and only after 3 months sent him to hospital where he was misdiagnosed with constipation, and eventually referred to the cancer hospital.' (PvM283, Mother of 4-year-old son; acute lymphoblastic leukaemia)

A wide variety of poor services was mentioned $(n=48)$ with specific challenges being delays in cancer detection $(n=7)$, a lack of confidence in primary health care services $(n=16)$, inadequate rural transport to hospitals $(n=2)$, errors in diagnosis at the secondary care levels $(n=4)$ and fears about delays and worsening symptoms $(n=6)$. Health care workers $(n=3)$ observed children arriving with end stage disease after parents had been taking them to clinics and doctors for many months. The challenge of negotiating referral pathways $(n=4)$ was aggravated by distance from tertiary treatment units, and some contributors $(n=7)$ had to navigate three or more steps in the referral to tertiary oncology care.

Other service-related challenges included delays, overcrowded waiting rooms, broken radiation machines, dirty facilities, unavailability of treatments and medications $(n=12)$, wards being under resourced $(n=5)$, poor infection control $(n=6)$, poor conditions for parents staying with children $(n=4)$, lack of community support or palliative care $(n=2)$, no bone marrow transplant treatment $(n=1)$, disrespect for the dignity, comfort and rights of children or their parents $(n=7)$, nurses and doctors uncaring $(n=9)$ and the lack of psychosocial services $(n=9)$. Positive feedback about good services $(n=26)$ included staff being helpful and kind $(n=7)$, a positive health facility $(n=3)$, medical team offering high quality professional care $(n=15)$, always being allowed to stay with one's child $(n=3)$, doctors being open and communicative $(n=5)$, appreciation for psychosocial services $(n=1)$ and gratitude for the CHOC interim care home facilities $(n=7)$.

\section{Financial challenges theme}

'I worry about what my family at home will eat because we used all our money to come for treatment.' (PvM311, Grandmother of 7-year-old grandson; kidney cancer)

Financial stress was frequently reported $(n=24)$ with limited and fixed family incomes being particularly vulnerable $(n=6)$ and parental fear of not being able to provide for the family needs being common $(n=32)$. Loss of work $(n=23)$ and threats to employment security $(n=6)$ loss of income $(n=14)$, additional expenses $(n=15)$, transport costs $(n=5)$, treatment costs $(n=3)$, special nutritional food costs $(n=2)$, provisions for being away from home $(n=4)$ and poverty $(n=4)$ all contributed to financial challenges.
Conditions of severe financial distress $(n=33)$, shortages of food, safe shelter, napkins, milk for babies and so on $(n=7)$ and shortages of special requirements to support their child $(n=8)$ were also noted. Challenges of poverty such as living on very small grants $(n=7)$ (e.g. child support grant R350 per month, disability grant R1510 per month, old age pension R1510 per month), ${ }^{18}$ unemployment $(n=4)$, single parenting $(n=2)$ and lack of availability of financial assistance $(n=10)$ were reported.

\section{Transport and travel challenges theme}

'I was not allowed to stay with my child at the hospital so when he was transferred I met the transport and saw that he was on the floor of the ambulance on his knees, the nurse at the regional hospital was very angry to see my child transported in this way.' (PvM288, Mother of 8-year-old son; acute lymphoblastic leukaemia)

Twenty-two of the 50 patient-contributors who lived further than $50 \mathrm{~km}$ from an oncology treatment centre, and three of the eight who lived within $50 \mathrm{~km}$ of a treatment centre, experienced transport challenges. Transport challenges were a worry and a financial burden $(n=12)$, with travelling long distances $(n=5)$, long waits and sleeping on chairs and benches overnight at pickup points $(n=6)$ and not having money for transport to pick-up point $(n=4)$ being reported as challenging. Logistics of transport was routinely managed by hospitals but problems were difficult to sort out $(n=10)$, for example vehicles being full on arrival $(n=2)$ and difficulties with organising transport at short notice $(n=2)$. A distressing transport challenge was having to cope with separation from family $(n=16)$, and because of financial constraints, one 11-year-old girl travelled unaccompanied return from Carnarvon to the tertiary hospital at Kimberly $(800 \mathrm{~km})$.

\section{Stigma challenges theme}

'I was scared that my neighbours would think that I was cursed because my husband died and now my grandson has cancer.' (PvM284, Grandmother of 10-year-old grandson; acute lymphoblastic leukaemia)

Cultural beliefs and practices $(n=7)$, a lack of knowledge of cancer $(n=6)$, belief that cancer is related to evil spirits $(n=6)$ and that tumours, baldness or paralysis indicated bewitchment $(n=3)$ were noted as contributing to stigma. Some families and fathers tried to refute that their children had cancer and withheld support $(n=6)$, while some mothers first took their children to a traditional healer for many months $(n=2)$ before being granted family permission to seek state medical care $(n=2)$.

Beliefs were reported that cancer was a death sentence $(n=3)$, only happened to people who were European $(n=7)$, was infectious ( $n=7)$ and was deserving of isolation $(n=7)$. Some contributors chose isolation and silence to avoid social embarrassment and discrimination $(n=6)$, and this was illustrated when children avoided school for fear of being 
shunned $(n=6)$. Shame and embarrassment at a child having cancer was well reported amongst family members $(n=26)$ and could be attributed to ignorance or misconception $(n=11)$. Shame encouraged secrecy of diagnosis $(n=8)$ and avoidance of extended family $(n=3)$, which all contributed to isolation from support $(n=7)$. One contributor described a brave response to stigma when she made a decision not to 'hide' her baby, and was rewarded when her community was supportive.

\section{Schooling challenges theme}

'My child failed grade one and has to redo it, but there is no schooling at the hospital, I am very worried about her education.' (PvM252, Mother of 6-year-old daughter; leukaemia)

Parental concern for loss of schooling and the threat to education and future prospects $(n=16)$ was common. Disruptions to schooling was because of travelling to hospital, discomforts of cancer and treatments, loss of contact with home school teachers and parents not able to help their children with school work $(n=16)$. Problems with hospital-schooling included language barriers $(n=2)$, no school service or too few teachers $(n=9)$. Some young parents dropped out of their own schooling $(n=2)$ and tertiary studies $(n=2)$, and children with cancer missed school $(n=6)$, valued home school teacher support $(n=5)$, had dropped out of school $(n=6)$ and were at high risk of dropping out $(n=3)$.

\section{Discussion}

In SA, the many challenges to the early diagnosis of childhood cancer and necessary access to care can be unmanageable for many and the consequences are late presentation of symptoms or abandonment of treatment. 19,20,21 $^{2}$ It is evident from this study that many family members and parents of children with cancer persist through challenges and ultimately get their children to tertiary paediatric oncology centres.

The limitations of this study were the small sample size, the uneven distribution of the sample across the country and the minimal feedback about palliative care. Strengths of the study were that the methodology was engaging and userfriendly, and that the use of translators and skilled interviews ensured that illiteracy and indigenous languages were not exclusion criteria despite having to contend with the country's 11 official languages. ${ }^{22}$

Almost all contributors noted emotional challenges as a factor in dealing with cancer and as has been previously found, ${ }^{23}$ young children with cancer were more scared of treatments than of cancer and coped as long as they were secure with their guardians. Parents were the ones who struggled with intense trauma, distress and anxiety. ${ }^{24}$ Being able to care for one's child is known to help parents of children with cancer to cope, and supporting parental coping is a recognised strategy which, in turn, is strengthening for their children..$^{23,24,25}$
Parents' emotional distress was frequently reported as overwhelming ${ }^{25}$ and was caused by the burden of lifestyle $\operatorname{cost}_{,}{ }^{26}$ maintaining family life, financial pressures, travelling away from home to childhood oncology treatment centres, separation from other children and a sense of powerlessness to protect one's child. For adolescents and teenagers, the emotional struggle of being separated from friends, awareness of the risk of death ${ }^{25,27}$ and missing important childhood experiences ${ }^{28,29}$ requires targeted interventions given the special emotional needs of this age group. ${ }^{27,30}$ Positive emotional coping was related to rewarding peer patient and peer-parent relationships, positive medical care, deepening of family relationships and growth of spiritual faith. Appreciation for good communication, ${ }^{19}$ kindness and good medical care confirms other findings that positive regard by medical personnel is a significant stress-reducing factor. ${ }^{31}$ Many participants reported emotional benefit from the interview process $(n=31)$ and most indicated that the research interview was their first real opportunity to speak about their experience, which coincidentally evidences the lack of psychosocial support services through the trajectory of cancer care. ${ }^{32}$

Poor standards of information, and lack of cancer knowledge by primary and other health care workers, is concerning. ${ }^{8,33}$ Busy medical teams, lack of information material in local African languages, illiteracy and lack of translators or multilingual medical personnel all act as barriers to information. Difficulty with access to information or not understanding information within the medical setting can encourage feelings of powerlessness, which, in turn, can lead to dissatisfaction with care. ${ }^{31}$ In this study, a number of parents lacked understanding of their children's cancer and expressed uncertainty about how to administer medication or manage infection control at home and, as reported in other findings, lack of discharge and palliative care support was problematic. .,34,35 $^{2}$

Physical and treatment challenges were indicated in $41 \%$ of the patient interviews and competent care that kept children's suffering and discomfort to a minimum was highly valued. Guardians tended to take the brunt of caring for smaller children with cancer, and teenagers were bothered by more adult concerns and questions. Permanent disabilities, disfigurement, psychological changes, blindness, paralysis, aphasia, cancer recurrence or advanced stage cancer highlighted extreme levels of suffering with far-reaching implications for young patients and their families. Challenges with a lack of community services, home care and palliative care have been acknowledged in the World Health Organization global survey on palliative care $\mathrm{e}^{5,34}$ and the need for a structured community palliative care strategy for paediatric oncology is a national advocacy priority. Although the lack of knowledge of cancer by many traditional healers can delay access to treatments, traditional healers are an important health resource for many communities and should be offered structured cancer education and respectful collaboration. ${ }^{19}$ 
Powerlessness was a commonly reported theme and in one of its most serious forms, parents and guardians were excluded from children's medical examinations or prevented from staying in hospital (primary or regional hospitals) with young cancer patients who were older than 7 years. This practice has been observed in other studies ${ }^{36}$ and besides being draconian and emotionally traumatic for all, is at odds with both constitutional ${ }^{37}$, and children's rights $^{38}$ and poses a safety risk to children who are denied a dedicated adult guardian at a time when they are extremely vulnerable. ${ }^{36,39}$ Being assertive in the face of powerlessness was difficult for many patient-participants and both language barriers ${ }^{40}$ and poor communication between the medical team and parents or guardians ${ }^{31}$ compounded this problem. Communication is an essential element of patientcentred care ${ }^{41}$ and the onus is on the medical team to communicate and collaborate in a therapeutic alliance with children with cancer and their families. ${ }^{29,42}$ Empowerment through patient-centred care redresses imbalances of power relations in the health setting ${ }^{40,42}$ and encourages positive cooperation and well-being ${ }^{43}$ in young cancer patients and their parents or guardians.

As previously documented, ${ }^{2,19}$ this study found that lack of public health awareness, misdiagnosis, poor cancer diagnostic skills at primary care clinics, incorrect treatments, unproductive admissions to regional hospitals and long waits for appointments all contributed to delays in children with cancer reaching tertiary oncology units. Despite the financial limitations of many families, when access to care became problematic, many participants searched for alternatives such as private doctors and pharmacies or even travelled to other towns.

Patient-centredness refers to an approach to medical care that is responsive to and respectful of patient needs and where patient values guide the clinical process. ${ }^{44}$ A lack of patient-centred care in a variety of settings was mentioned by patient-contributors and some nurses were harshly criticised. This feedback reflects the stresses under which the nursing profession works in SA and highlights the urgent need for supportive management and training in patientcentred care. The current primary and district health system in SA is the entry point for many children who have symptoms of cancer, and clinic staff should be trained to use primary care algorithms that include cancer detection and care guidelines. ${ }^{45}$ Notwithstanding these challenges, there were occasions when referral pathways were efficient, medical teams were skilled and referrals to tertiary oncology centres were well expedited. Separation from home was a critical challenge for families and the CHOC care homes were an invaluable resource.

Most South Africans are dependent on the no-cost public clinics, hospitals and transport for access to health care services. ${ }^{36}$ The financial burden of additional unavoidable $\operatorname{costs}^{26}$ incurred in the process of accessing cancer care can create unmanageable financial pressures ${ }^{20,46}$ which can contribute to the risk of treatment abandonment. ${ }^{36,46}$ Financial assistance was inadequate for many families coping with childhood cancer, and financial aid and labour legislation to address threats to employment or compassionate leave for parents are needed.

Transport challenges are well known as a treatment burden for vulnerable patients with cancer in both local-to-treatment and distant-to-treatment samples. ${ }^{47}$ In this study, most of the childhood patients with cancer (77\%) had to travel far away from home for treatment and the separation of families was an onerous challenge. Practical transport challenges included long waits (even sleeping overnight on benches or on the floor) for pickup, harsh travel conditions, difficulties with bookings, costs, struggles accessing information and frustration with rectifying problems.

Stigma, ignorance and poor public awareness of cancer are all interrelated factors that contribute to poor outcomes and can lead to shame, fear, embarrassment, isolation and a feeling of lesser worth. Some cancer stigma is entrenched in traditional culture and beliefs and shapes health-seeking decisions ${ }^{19}$ and can perpetuate misconceptions about cancer. Children were also noted as particularly vulnerable in the school system where the stigma of cancer could lead to fearfulness and rejection by peers because of fearfulness of cancer, visible tumours, alopecia or just looking different.

A significant number of parents expressed concern that their children were missing out on school and six children in the sample had completely dropped out of school and three others were under severe threat of dropping out. Children who managed to maintain school work tended to have an ongoing relationship with teachers from their home school and active parental involvement. A few young parents had to abandon their own schooling and tertiary education, which highlights an area for targeted counselling to support parents to resume their studies. Where hospitals were fortunate to have schooling services, language differences, inconsistent contact with teachers and children having a wide range of learning needs were also challenges.

\section{Conclusion}

This qualitative and on-the-ground perspective of cancerrelated challenges makes an important contribution to the recognition and understanding of childhood cancer-related challenges in a low-resource setting, and to the development of solution-focused cancer advocacy. ${ }^{3}$ The findings identify that poor medical services, poor psychosocial care and lack of prioritising of cancer in national health care contribute to many emotional, social and practical challenges for young South African patients with cancer and their families. ${ }^{7,8,33}$

The main cancer-related challenges that were reported in the photovoice interviews included lack of awareness and knowledge about cancer at the traditional healing level, primary and regional health care levels, lack of patientcentred care, undesirable separation of children with cancer from family and guardians, exclusion of parents or guardians 
as important members of the care team, lack of targeted counselling for the special needs of teenagers and the lack of community and palliative care support for paediatric oncology. Recommendations include educational outreach to schools and traditional healers, training on childhood cancer at the primary and secondary health care levels, improvements to hospital transport and firm protocols for keeping children with their caregivers.

Recommendations for further research include community and palliative care for children, the care of children with cancer who have permanent disabilities, and problems with access to financial assistance. These findings highlight the need for improved cancer planning as well as an emphasis on the early detection of cancer in SA.48

\section{Acknowledgements}

The authors would like to thank the Medical Research Council of South Africa for the ethical approval process (EC006-3/2004); the 476 Charitable Trust for financial assistance for phase I; the National Cancer Association of South Africa (CANSA) for a research grant for phase II; those who volunteered professional services and personal time; the CHOC for access and support in the patient interview process; and the young cancer patients, family members and oncology care workers for the generosity of their photo-stories.

\section{Competing interests}

The authors have no conflicts of interest to disclose and confirm that this work is original, has not been published elsewhere, nor is it currently under consideration for publication elsewhere.

\section{Authors' contributions}

L.B.E. was the co-principal investigator of this study and was responsible for research design, ethical review and approval submissions, data collection, data analysis and preparation of the manuscript. L.E.G. was the co-principal investigator of this study and was responsible for advocacy liaison, data collection, data analysis and development of recommendations for advocacy.

\section{References}

1. Hadley LG, Rouma BS, Saad-Eldin Y. Challenge of pediatric oncology in Africa. Semin Pediatr Surg. 2012;21(2):136-141. https://doi.org/10.1053/j.sempedsurg. 2012.01.006

2. Chirdan LB, Bode-Thomas F, Chirdan OO. Childhood cancers: Challenges and strategies for management in developing countries. Afr J Paediatr Surg. 2009; 6:126-30. https://doi.org/10.4103/0189-6725.54783

3. Haileamlak A. The challenge of childhood cancer in developing countries. Ethiop J Health Sci. 2016;26(3):199-200. https://doi.org/10.4314/ejhs.v26i3.1

4. Yao JJ, Couitchere L, Atimere Y, et al. Childhood cancer in Côte d'Ivoire, 1995-2004challenges and hopes. S Afr Med J. 2012;103(2):113-115. https://doi.org/10.7196/ SAMJ.6365

5. Stefan DC. Cancer care in Africa: An overview of resources. J Glob Oncol 2015;1(1):30-36. https://doi.org/10.1200/JGO.2015.000406

6. Stefan DC, Stones DK, Wainwright D, Kruger M, Davidson A, Poole J, et al. Childhood cancer incidence in South Africa, 1987-2007. S Afr Med J. 2015;105(11):939-947. https://doi.org/10.7196/SAMJ.2015.v105i11.9780
7. American Cancer Society. Cancer in Africa [homepage on the Internet]. Atlanta, GA: International Agency for Research on Cancer, 2011 [cited 2016 Dec 22]; p. 1-16. Available from: http://www.cancer.org/acs/groups/content/@ Dec 22]; p. 1-16. Available from: http://www.cancer.org/acs/grou
epidemiologysurveilance/documents/document/acspc-031574.pdf

8. Price AJ, Ndom P, Atenguena E, Nouemssi JP, Ryder RW. Cancer care challenges in developing countries. Cancer. 2012;15:3627-3635. https://doi.org/10.1002/ cncr.26681

9. Strother RM, Asirwa FC, Busakhala NB, et al. AMPATH-oncology: A model for comprehensive cancer care in sub-Saharan Africa. J Cancer Policy. 2013;1(3-4): e42-e48. https://doi.org/10.1016/j.jcpo.2013.06.002

10. Wang C, Burris M. Empowerment through photo novella: Portraits of participation Health Educ Quart. 1994;21:171-186. https://doi.org/10.1177/109019819402100204

11. Han CS, Oliffe JL. Photovoice in mental illness research: A review and recommendations. Health (London, England:1997). 2016;20(2):110-126. https:// doi.org/10.1177/1363459314567790

12. Balbale SN, Locatelli SM, LaVela SL. Through their eyes; lessons learned using participatory methods in health care quality improvement projects. Qual Health Res. 2016;26(10):1382-92. https://doi.org/10.1177/1049732315618386.2016

13. Kim MA, Yi J, Sang J, Kim SH, Heo IY. Experiences of Korean mothers of children with cancer: A photovoice study. J Psychosoc Oncol. 2016;0:1-20. https://doi.org/ 10.1080/07347332.2016.1263265

14. Wang CC, Morrel-Samuels S, Hutchinson PM, Bell L, Pestronk RM. Flint photovoice: Community building among youths, adults, and policymakers. Am J Public Health. 2004;94(6):911-913. https://doi.org/10.2105/AJPH.94.6.911

15. Wang C, Yi WK, Tao ZW, Carovano K. Photovoice as a participatory health promotion strategy. Health Promot Int. 1998;13(1):75-86. https://doi.org/ 10.1093/heapro/13.1.75

16. Elo $S$, \& Kyngäs $H$. The qualitative content analysis process. J Adv Nurs 2008;62(1):107-115. https://doi.org/10.1111/j.1365-2648.2007.04569.x

17. Tracey S. Qualitative research methods; collecting evidence, crafting analysis, communicating impact. 2013. Oxford UK: Wiley-Blackwell.

18. Social benefits [homepage on the Internet]. Pretoria, South Africa: South African Government; 2017. Available from: http://www.gov.za/services/servicesresidents/social-benefits

19. Venter M, Venter C, Botha K. Cancer treatment in South Africa: A narrative literature review. J Psychol in Africa. 2012;22(3):459-466.

20. Kankeu HT, Saksena P, Xu K, Evans DB. The financial burden from non-communicable diseases in low- and middle-income countries: A literature review. Health Res Policy Syst. 2013;11(31):1-12. https://doi.org/10.1186/1478-4505-11-31

21. Slone JS, Chunda-Liyoka C, Perez M, et al. Pediatric malignancies, treatment outcomes and abandonment of pediatric cancer treatment in Zambia. PLoS One. 2014;9(2):1-8[e89102]. https://doi.org/10.1371/journal.pone.0089102

22. Statistics SA. Statistical release P0302 mid-year population estimates. Pretoria: Statistics SA; 2014

23. Hildenbrand AK, Clawson KJ, Alderfer MA, Marsac ML. Coping with pediatric cancer: Strategies employed by children and their parents to manage cancerrelated stressors during treatment. J Pediatr Oncol Nurs. 2011;28(6):344-354. https://doi.org/10.1177/1043454211430823

24. Van Dongen-Melman JE, Van Zuuren FJ, Verhulst FC. Experiences of parents of childhood cancer survivors; a qualitative analysis. Patient Educ Couns. 1998;34(3):185-200. https://doi.org/10.1016/S0738-3991(98)00031-7

25. Cernvall M, Carlbring P, Ljungman, G, Von Essen L. Guided self-help as intervention for traumatic stress in parents of children with cancer: Conceptualization, intervention strategies, and a case study. J Psychosoc Oncol. 2013;31(1):13-29. https://doi.org/10.1080/07347332.2012.741095

26. Tsimicalis A, Stevens B, Ungar WJ, Mc Keever P, Greenberg M. The cost of childhood cancer from the family's perspective: A critical review. Pediatr Blood Cancer. 2011;56:707-717. https://doi.org/10.1002/pbc.22685

27. Maggiolini A, Grassi R, Adamoli L, et al. Self-image of adolescent survivors of longterm childhood leukemia. J Pediatr Hematol Oncol. 2000;22(5):417-421. https:// doi.org/10.1097/00043426-200009000-00006

28. Yi J, Zebrack B. Self-portraits of families with young adult cancer survivors: Using photovoice. J Psychosoc Oncol. 2010;28(3):219-243. https://doi.org/10.1080/ 07347331003678329

29. Morales GI. Photovoice with pediatric cancer parents: Understanding difficulties and communicative behaviors for coping effectively. 2012. El Paso: ETD Collection for University of Texas. AAl1513111.

30. Zebrack B, Kent EE, Keegan T, Kato I, Smith AW, Aya Hope Study Collaborative Group. Cancer sucks, and other ponderings by adolescent and young adult cance survivors. J Psychosoc Oncol. 2014;32(1):1-13. https://doi.org/10.1080/0734733 2.2013.855959

31. Attree, M. Patients' and relatives' experiences and perspectives of 'good' and 'not so good' quality care. J Adv Nurs. 2001;33:456-466. https://doi.org/10.1046/ j.1365-2648.2001.01689.x

32. Egan R, McKechnie R, Jobson J, Herbison P, Richards R. Perspectives on psychosocial and spiritual cancer support services in New Zealand. J Psychosoc Oncol. 2013;31(6):659-674. https://doi.org/10.1080/07347332.2013.835017

33. Busolo DS, Woodgate RL. Cancer prevention in Africa: A review of the literature. Glob Health Promot. 2015;22:3-39. https://doi.org/10.1177/1757975914537094

34. Ganca LL, Gwyther L, Harding R, Meiring M. What are the communication skills and needs of doctors when communicating a poor prognosis to patients and their families? A qualitative study from South Africa. S Afr Med J. 2016;106(9):94-944. https://doi.org/10.7196/SAMJ.2016.v106i9.10568 
35. Mosavel M, Sanders KD. Photovoice: A needs assessment of African American cancer survivors. J Psychosoc Oncol. 2010;28(6):630-643. https://doi.org/10.108 $0 / 07347332.2010 .516809$

36. Goudge J, Gilson L, Russell S, Gumede T, Mills A. Affordability, availability and acceptability barriers to health care for the chronically ill: Longitudinal case studies from South Africa. BMC Health Serv Res. 2009;9(1):1-18. https://doi. org/10.1186/1472-6963-9-75

37. Constitution of the Republic of South Africa No 108 of 1996 [homepage on the Internet]. Second Amendment Act, No 3 of 2003. 1996 [cited 2016 Oct 29]. Issue 38, p. 6-11. Available from: http://www.gov.za/sites/www.gov.za/files/images/ a108-96.pdf

38. Children's Act 38 of 2005 (amended by Children's Amendment Act 41 of 2007 and Child Justice Act 75 of 2008) [homepage on the Internet]. 2005. Section 129:59, Section 32(2):32. Available from: http://www.justice.gov.za/legislation/acts/2005$038 \% 20$ childrensact.pdf

39. Rotherham local safeguarding children manual: Contact between parents and their children in hospital where there are safeguarding concerns [homepage on the Internet]. Rotherham, UK: Rotherham Safeguarding Children Board; 2016 [cited 2016 Oct 3]. Available from: http://rotherhamscb.proceduresonline.com/ chapters/p_par_ch_hosp.htm

40. Nugus P, Greenfield D, Travaglia J, Westbrook J, Braithwaite J. How and where clinicians exercise power: Interprofessional relations in health care. Soc Sci Med [serial online]. 2010 [cited 2016 Sep 14];71(5):898-909. https://doi.org/10.1016/].

41. Govender M, Bowen RC, German ML, Bulaj G, Bruggers CS. Clinical and neurobiological perspectives of empowering pediatric cancer patients using videogames. Games Health J. 2015;4(5):362-374. https://doi.org/10.1089/g4h.2015.0014
42. Seth T. Communication to pediatric cancer patients and their families: A cultural perspective. Indian J Palliat Care. 2010;16(1):26-29. https://doi.org/10.4103/ 0973-1075.63131

43. Arbuthnott A, Sharpe D. The effect of physician-patient collaboration on patient adherence in non-psychiatric medicine. Patient Educ Couns. 2009;77(1):60-67. https://doi.org/10.1016/j.pec.2009.03.022

44. Institute of Medicine (US) Committee on Psychosocial Services to Cancer Patients/ Families in a Community Setting. Cancer care for the whole patient: Meeting psychosocial health needs. Adler NE, Page AE, editors. Washington, DC: National US Academies Press; 2008.

45. University of Cape Town Lung Institute. Primary care 101 guidelines. Pretoria, South Africa: National Department of Health; 2013/2014.

46. Goudge J, Russell S, Gilson L, Gumede T, Tollman S, Mills A. Illness-related impoverishment in rural South Africa: Why does social protection work for some households but not others? J Int Dev. 2009;21(2):231-251. https://doi.org/ 10.1002/jid.1550

47. Syed ST, Gerber S, Sharp LK. Traveling towards disease: Transportation barriers to health care access. J Commun Health. 2013;38(5):976-993. https://doi.org/ 10.1007/s10900-013-9681-1

48. Parkin DM, Ferlay J, Hamdi-Chérif M, et al. Cancer in Africa: Childhood cancers [homepage on the Internet]. IARC France. International Agency for Research on Cancer, WHO Scientific Publication No. 153. (E-Reader Version). Lyon Press, 2013 [cited 2016 Sep 14]; p. 381-396. Available from: http://www.iarc.fr/en/ publications/pdfs-online/epi/sp153/SP153-10.pdf 